\title{
Effects of Some Antihypertensive Drugs on the Metabolism and Pharmacokinetics of Indapamide in Rats
}

\author{
Fang $\mathrm{Yan}^{1}$, Ying $\mathrm{Hu}^{1}$, Bin $\mathrm{Di}^{1,2}$, Ping Lei $\mathrm{He}^{1}$ and Guibin $\mathrm{Sun}^{3}$ \\ ${ }^{1}$ Department of Pharmaceutical Analysis, China Pharmaceutical University, Nanjing, P.R. China \\ ${ }^{2}$ Key Laboratory of Drug Quality Control and Pharmacovigilance, Ministry of Education, Nanjing, P.R. China \\ ${ }^{3}$ Nanjing China Tianqing Pharmaceutical Co., LTD, Nanjing, P.R. China
}

Received, August 12, 2011; Revised, January 5, 2012; Accepted, January 10, 2012; Published, January 11, 2012.

\begin{abstract}
Purpose. Indapamide, a non-thiazide antihypertensive diuretic agent, has been widely coadministered with other classes of antihypertensive agents to reach target systolic blood pressure. Indapamide is extensively metabolized by cytochromes P450. Interaction of indapamide and other antihypertensive drugs are unknown. We investigated the effects of other antihypertensive drugs on the metabolism and pharmacokinetics of indapamide in vitro and in vivo. Methods. Indapamide metabolism was studies in vitro using human liver microsomes pretreated with or without different concentrations of CYP-selective inhibitors and seven major antihypertensive drugs, felodipine, nifedipine, nitrendipine, telmisartan, irbesartan, valsartan and puerarin. Furthermore, the pharmacokinetics of indapamide was determined by HPLC-MS/MS to evaluate the effects of felodipine coadministered on the bioavailability of indapamide in rats in vivo. Results. The Km and Vmax of indapamide metabolism were $114.35 \pm 3.47 \mu \mathrm{M}$ and $23.13 \pm 6.61 \mu \mathrm{mol} / \mathrm{g} / \mathrm{min}$. The metabolites of indapamide, hydroxyl-indapamide and dehydrogen-indapamide, were followed. CYP3A4 and CYP2C19 were involved in indapamide metabolism in human live microsomes. In addition, felodipine, nifedipine and nitrendipine significantly inhibited indapamide metabolism with the maximum inhibitory rates of $82.6 \%, 72 \%$ and $95 \%$, respectively. Felodipine significantly elevated indapamide plasma concentration and prolonged its half-life. Conclusions. Combination therapy of indapamide and felodipine might lead to the alteration of indapamide metabolism and pharmacokinetics. The consequence of such an interaction that may include increased effectiveness and side effect needs to be tudeis in human.
\end{abstract}

This article is open to POST-PUBLICATION REVIEW. Registered readers (see "For Readers") may comment by clicking on ABSTRACT on the issue's contents page.

\section{INTRODUCTION}

Indapamide, 3-(aminosulfonyl)-4-chloro-N-(2, 3-dihydro-2-methyl-1H-indol-1-yl) benzamide, is a non-thiazide antihypertensive diuretic agent which contains sulfamoyl chlorobenzamide and methylindoline groups. It has been widely used for its mild and sustained antihypertensive effect when administered orally at low doses.

Recently, most patients clinically require two or more classes of antihypertensive agents to reach their target systolic blood pressure and this combination therapy has become standard practice in the contemporary management of hypertension (1). It has been reported that the combination of a low dose $(2 \mathrm{mg})$ of perindopril, an angiotensin-converting enzyme inhibitor, and a low dose $(0.625 \mathrm{mg})$ of indapamide, can result in greater blood pressure reduction and less albumin excretion $(2,3)$. A recent large Phase III clinical trial $(11,140$ patients in the advance trial in twenty countries) of a fixed-dose combination of these two drugs showed significantly reduced risks of major vascular events in patients with type 2 diabetes mellitus (4). Though proved to be the most effective means of achieving target blood pressure values by clinical trials, particularly in the large number of patients in whom monotherapy is ineffective, this combination therapy of indapamide and other antihypertensive agents probably leads to potential drug-drug interactions which is a particularly important type of adverse drug event.

Drug-drug interactions may occur if the expression levels and activities of cytochrome P450 are influenced by another drug, and interactions can lessen or magnify the desired therapeutic effect of a drug, or may cause unwanted or unexpected side effects (5).

Corresponding Author: Bin Di, Ph.D., Department of Pharmaceutical Analysis, China Pharmaceutical University, Nanjing, P.R. China, E-mail: cpudibin@hotmail.com 
Indapamide is extensively metabolized to 19 metabolites by CYP with less than $5 \%$ found unchanged in urine $(6,7)$. However, the reports on adverse effects and drug-drug interactions of indapamide are mostly involved in pharmacological activities, in which patients administrated with recommended doses of indapamide had severe hyponatremia, fluid and electrolyte imbalances, glucose tolerance and calcium excretion, et al (8-11). There are not any study on potential pharmacodynamic action and safety of indapamide with liver CYP-mediated drug interactions.

In clinical application, indapamide is often combined with one of the seven major antihypertensive drugs, felodipine, nifedipine, nitrendipine, telmisartan, irbesartan, valsartan and puerarin (12-18) in therapeutic regimens of Chinese patients with cardiovascular disease to reduce side effects or toxicity and achieve more blood pressure lowering than up-titration of the monotherapy alone. In addition, these seven antihypertensive drugs are metabolized by CYP or alter the CYP activities (19-25). We hypothesized that the coadministration of indapamide and seven other antihypertensive drugs would possibly modify the metabolism of indapamide. Herein, we report a study of the comparative metabolism kinetics and of indapamide and its metabolites by human liver microsomes treated with or without CYP-selective inhibitors and the seven antihypertensive drugs using HPLC-UV and HPLC-MS/MS. The pharmacokinetic interaction of indapamide and felodipine was assessed by concentration-time profiles and main pharmacokinetic parameters of indapamide in rats in vivo.

\section{MATERIALS AND METHODS}

\section{Materials and reagents}

Indapamide, $\alpha$-naphthoflavone, sulfaphenazole, ticlopidine, quinidine, 4-methylpyrazole and ketoconazole were purchased from Sigma Chemical Co. (St Louis, MO). Telmisartan, felodipine, irbesartan, valsartan, puerarin, nifedipine and nitrendipine were purchased from National Institute for the Control of Pharmaceutical and Biological Products of China (Beijing, China). <Beta>-nicotinamine adenine dinucleotide phosphate (NADPH) in reduced form was purchased from Roche Co. (Basel, Switzerland). Pooled human liver microsomes were purchased from BD Biosciences (San Jose,
CA). Tris (hydroxymethyl) aminomethane (Tris, ultra pure grade) was purchased from Angus Co. (Illinois, USA). Methanol (HPLC grade) was obtained from Tedia Co. (Fairfield, OH, USA). Ammonium acetate was of analytic-grade purity and purchased from Nanjing Chemical Reagent Co. Ltd. (Nanjing, P.R. China). Deionized water was purified through PL5242 Purelab Classic UV (PALL Co. Ltd., USA) before use. All materials were of the highest grade available.

\section{Animals}

Male Sprague-Dawley rats $(220 \pm 10 \mathrm{~g})$ were supplied by the Animal Central of the Chinese Academy of Science in Shanghai (Shanghai, China) and housed in an air-conditioned animal quarter at a temperature of $22 \pm 2^{\circ} \mathrm{C}$ and a relative humidity of $50 \pm 10 \%$, and kept on a $12 \mathrm{~h}$ light/dark cycle with free access to food. The animals were fasted for $12 \mathrm{~h}$ prior to dosing. All animal experiments were carried out according to Guideline for the Care and Use of Laboratory Animals, and approved by the Animal Ethics Committee of China Pharmaceutical University.

\section{Equipments and chromatographic conditions} Chromatographic HPLC-UV assay of kinetic analysis and inhibition of indapamide metabolism by CYP-selective inhibitors and antihypertensive agents in vitro, was performed on Shimadzu 2010 HPLC system equipped with a quaternary pump, an autosampler and UV detector (Shimadzu, Kyoto, Japan). The substrates were separated on $4.6 \mathrm{~mm} \times 250 \mathrm{~mm}$ and $5 \mu \mathrm{m}$ particle size of AichromBond-1 C18 column (Agilent, USA) with a mobile phase consisted of $55 \%$ methanol and $45 \%$ water (containing $0.2 \%$ ammonium acetate) on the wavelength of $240 \mathrm{~nm}$ at the flow rate of $1.0 \mathrm{~mL} / \mathrm{min}$.

Thermo-Finnigan TSQ Quantum Ultra tandem mass spectrometer equipped with an electrospray ionization source (San Jose, CA, USA), a Finnigan surveyor LC pump and an auto sampler were used for the HPLC-MS/MS analysis of identification of indapamide metabolites and pharmacokinetics of indapamide with or without felodipine in rats in vivo. Data acquisition was performed with Xcalibur 1.4 software (Thermo-Finnigan, San Jose, CA, USA).

Chromatographic assay of identification of indapamide metabolites was performed according to the chromatographic condition of kinetic analysis of indapamide metabolism. The mass spectrometers were operated in the positive ion detection mode with the spray voltage set at 5000 
V. The heated capillary temperature was $300^{\circ} \mathrm{C}$. The nitrogen sheath gas and the auxiliary gas were set at 35 and 5 psi, respectively. All parameters were optimized by infusing the analyte in mobile phase at a flow rate of 0.1 $\mathrm{mL} / \mathrm{min}$. The fragment ions were produced by collision-induced dissociation of the selected precursor ions with the collision energy of $20 \mathrm{eV}$.

Chromatographic separations assay of pharmacokinetic of indapamide with or without felodipine in rats in vivo, were performed on 4.6 $\mathrm{mm} \times 250 \mathrm{~mm}$ and $5 \mu \mathrm{m}$ particle size of ZORBAX ODS column (Agilent, USA). The mobile phase of methanol-water containing $0.2 \%$ ammonium acetate $(64: 36, \quad \mathrm{v} / \mathrm{v})$ was used isocratically eluting at the flow-rate of $1 \mathrm{~mL} / \mathrm{min}$ and the total period for one sample was about 5 min. A $5 \mu \mathrm{L}$ sample was injected into the column and $30 \%$ of the eluent was split into the inlet of the mass spectrometer using an electrospray ionization source. The column temperature was maintained at $30^{\circ} \mathrm{C}$ and the autosampler was set at $4^{\circ} \mathrm{C}$. Parameters of mass spectrometer were selected according to identification of indapamide metabolites. Quantification was performed in the positive ion detection mode with selected reaction monitoring with argon at a pressure of $1.0 \mathrm{mTorr}$ for collision-induced dissociation of the following transitions: indapamide $\mathrm{m} / \mathrm{z} \quad 365.8 \rightarrow 132.1$ with the collision energy set at $20 \mathrm{eV}$, and glipizide (IS) $\mathrm{m} / \mathrm{z} 445.9 \rightarrow 167.0$ with collision energy set at 35 $\mathrm{eV}$.

\section{Validation Assay}

Calibration standards were prepared and assayed with indapamide concentration range of 1-1500 $\mathrm{ng} / \mathrm{mL}$ in rat whole blood and $1-120 \mu \mathrm{M}$ in human liver microsomes. The calibration curves were generated by plotting the peak area ratios of indapamide to the IS versus the concentrations of indapamide with $1 / \mathrm{C}^{2}$ weighted least-squares linear regression analysis. The acceptance criterion of a calibration curve was a correlation coefficient (r) of 0.99 or better, and that for each back-calculated standard concentration must be within $\pm 15 \%$ deviation from the spiked value ( $\pm 20 \%$ at the LLOQ).

Intra-day and inter-day validation studies for precision and accuracy were performed at three QC levels. The QC concentrations were set at 2, 80 and $1000 \mathrm{ng} / \mathrm{mL}$ in rat whole blood and 2, 60 and $100 \mu \mathrm{M}$ in human liver microsomes, respectively. To determine intra-day precision and accuracy, the assay was carried out on QC samples at different time points during the same day. Inter-day precision and accuracy were determined by assaying the QC samples over 5 consecutive days. The precision was expressed as R.S.D. (\%) and the accuracy was determined as by percentage between the mean measured concentrations and the spiked concentrations.

The extraction recovery of indapamide evaluated by analyzing five replicates concentrations at 2,80 and $1000 \mathrm{ng} / \mathrm{mL}$ in rat whole blood and 2, 60 and $100 \mu \mathrm{M}$ in human liver microsomes, respectively. The recovery was calculated by comparing the peak areas of the analysts in the spiked samples with those of the equivalent amounts of the analysts in the samples without extration.

\section{Microsomal incubation conditions}

Microsomal incubation conditions were established and controlled to provide a reproducible and linear rate of indapamide metabolism in vitro. A typical reaction mixture contained $100 \mathrm{mM}$ potassium phosphate buffer (pH 7.4), $1.0 \mathrm{~g} / \mathrm{L}$ microsomal protein and $100 \mu \mathrm{M}$ indapamide in the final volume of $0.5 \mathrm{~mL}$. The incubation mixture was preincubated at $37{ }^{\circ} \mathrm{C}$ for $5 \mathrm{~min}$ and reactions were initiated by adding 50 $\mu \mathrm{L}$ NADPH $(10 \mathrm{mM})$, then incubated at $37^{\circ} \mathrm{C}$ for the pre-selected intervals in a shaking water bath. The reaction system was terminated by adding 0.5 $\mathrm{mL}$ ice-cold acetonitrile (26).

Incubation of indapamide with CYP-selective inhibitors and antihypertensive drugs in human liver microsomes in vitro

Inhibition of indapamide metabolism in human liver microsomes was performed by incubating indapamide with or without the different concentration ranges of specific CYP inhibitors, such as $\alpha$-naphthoflavone (CYP1A2, 0.08-50 $\mu \mathrm{M}$ ), sulfaphenazole (CYP2C9, 0.04-10 $\mu \mathrm{M})$, ticlopidine (CYP2C19, 0.04-25 $\mu \mathrm{M}$ ), quinidine (CYP2D6, 0.02-12.5 $\mu \mathrm{M}$ ), 4-methylpyrazole (CYP2E1, 0.05-5 $\mu \mathrm{M})$ and ketoconazole (CYP3A4, 0.1-10 $\mu \mathrm{M})$ (27-32). The seven antihypertensive drugs, felodipine, nifedipine, nitrendipine, telmisartan, irbesartan, valsartan and puerarin, were often combined with indapamide in therapeutic regimens of Chinese patients with cardiovascular disease (12-18). Therefore, the drug-drug interactions of indapamide and these seven antihypertensive drugs were investigated in human liver microsomes in vitro. Maximum concentrations selected of these seven drug candidates in this study, were calculated with reference to human oral dose coadministered with 
indapamide in clinical (12-18). Series of concentrations were set at the different concentration ranges of felodipine (0.13-83.33 $\mu \mathrm{M})$, nifedipine (0.63-98.27 $\mu \mathrm{M})$, nitrendipine (0.14-86.56 $\mu \mathrm{M})$, telmisartan $(0.12-77.64 \mu \mathrm{M})$, irbesartan $(0.15-93.46 \mu \mathrm{M})$, valsartan $(0.15-91.95$ $\mu \mathrm{M})$ and puerarin $(1.54-961.54 \mu \mathrm{M})$. Incubation conditions and chromatographic assay had been described above. The CYP inhibitors and the seven antihypertensive drugs were added in a final volume of $0.5 \mathrm{~mL}$ and incubated with indapamide $(100 \mu \mathrm{M})$ for $30 \mathrm{~min}$. The reactions were stopped by adding $0.5 \mathrm{~mL}$ ice-cold acetonitrile. The samples were vortex-mixed for $5 \mathrm{~min}$ and centrifugated at $12,000 \mathrm{rpm}$ for $10 \mathrm{~min}$. A $20 \mu \mathrm{L}$ of the upper solution was analyzed by HPLC or HPLC-MS/MS systems to assess the effects of the CYP inhibitors and seven antihypertensive drugs on indapamide metabolism, and to determinate kinetic parameters as well as identify its metabolites.

\section{Administration of indapamide with felodipine in rats in vivo}

The rats were randomized into groups, each with six rats. The doses of indapamide and felodipine were selected according to the human doses and IC50 values of rats in the previous reports (12) and our pilot experiments. The control group was only orally administered indapamide at the dose of $0.25 \mathrm{mg} / \mathrm{kg}$ (suspended in edible oil). The test group was orally administered indapamide at the dose of $0.25 \mathrm{mg} / \mathrm{kg}$ with felodipine (dose of 0.9 $\mathrm{mg} / \mathrm{kg}$, suspended in edible oil). Blood samples $(250 \mu \mathrm{L})$ were collected in heparinized eppendorf tube via the oculi chorioideae vein at 0 (pre-dose), $0.25,0.75,1.5,2.5,3.5,5,7,9$ and $12 \mathrm{~h}$ post-dose, and stored at $-20^{\circ} \mathrm{C}$ until the day of analysis.

The pharmacokinetic study of indapamide was carried out according to the procedure as reported previously (33) with a modified pre-treatment method. A $20 \mu \mathrm{L}$ of glipizide solution (internal standard, $6 \mu \mathrm{g} / \mathrm{mL}$ ) and $3 \mathrm{ml}$ of acetic ether were added to $250 \mu \mathrm{L}$ of whole blood sample. The sample was vortexed for $3 \mathrm{~min}$ and centrifugated at $1,750 \mathrm{rpm}$ for $10 \mathrm{~min}$. The $2 \mathrm{~mL}$ of organic layer was transferred into another tube and the layer was evaporated to dryness at $40^{\circ} \mathrm{C}$ under a stream of nitrogen. The residual was reconstituted in $150 \mu \mathrm{L}$ of mobile phase and a 5 $\mu \mathrm{L}$ of this solution was injected for HPLC-MS/MS analysis.

\section{DATA ANALYSIS AND STATISTICS}

The kinetic parameters $\mathrm{Vmax}$ and $\mathrm{Km}$ of indapamide were calculated by nonlinear regression analysis (Program SigmaPlot 8.0; Enzyme Kinetics Module). Pharmacokinetic calculations were performed on the data of each individual experimental animal using the pharmacokinetic calculation software, WinNonlin Standard Edition Version $1.1 \quad$ (Scientific Consulting Inc., Apex, NC, USA). All the data were expressed as mean \pm standard deviation (S.D.). Results were analyzed using one-way ANOVA followed by Turdey post hoc test or Student's t-test. Differences with P values less than 0.05 were considered to be significant.

\section{RESULTS}

\section{Method Validation}

Typical calibration equations were $\mathrm{C}=120 \mathrm{~A}+0.0388 \quad(\mathrm{r}=0.9996)$ in rat whole blood and $\mathrm{C}=11 \mathrm{~A}+0.047(\mathrm{r}=0.9992)$ where $\mathrm{A}$ represents the peak area ratios of indapamide to the IS and $\mathrm{C}$ represents the sample concentrations of indapamide. The $\mathrm{CV}$ of intra-and inter-day assessments for both matrices were less than $15 \%$ (Table 1 and 2). Mean inter-day errors in rat whole blood and in human liver micriosomes were less than $5 \%$ (Table 1 and 2). The present method offered a LLOQ of $1 \mathrm{ng} / \mathrm{mL}$ with R.S.D. of $7.9 \%$ and the accuracy of $102.2 \%$ in $250 \mu \mathrm{L}$ rat whole blood sample. In $0.5 \mathrm{~mL}$ human liver microsomes sample, the LLOQ was $1 \mu \mathrm{M}$ with R.S.D. of $6.4 \%$ and the accuracy of $103.4 \%$. The LLOQs were sufficient for the pharmacokinetic and metabolic studies of indapamide in rats and human liver microsomes. The average recoveries were $89.1,94.1$ and $93.5 \%$ with 2,80 and 1000 $\mathrm{ng} / \mathrm{mL}$ indapamide in rat whole blood, respectively. In human liver microsomes, recovery was $95.6,97.7$ and $98.4 \%$ for 2,60 and $100 \mu \mathrm{M}$, respectively. The average extraction recoveries for IS were 87.3 and $97.1 \%$ in rat whole blood and human liver microsomes, respectively.

\section{Kinetics study and metabolites identification of indapamide in human liver microsomes}

The incubation conditions of indapamide metabolism in human liver microsomes were optimized in the previous studies (data not shown). To calculate enzyme kinetics parameters of indapamide metabolism, a series of substrate concentrations of indapamide $(5-200 \mu \mathrm{M}, \mathrm{n}=6)$ 
were incubated in human liver microsomes (protein content of $1.0 \mathrm{~g} / \mathrm{L}$ ) for $30 \mathrm{~min}$. The $\mathrm{Km}$ and Vmax of indapamide metabolism were 114.4 $\pm 3.5 \mu \mathrm{M}$ and $23.1 \pm 6.6 \mu \mathrm{mol} / \mathrm{g} / \mathrm{min}$, respectively.

Furthermore, the identification of indapamide metabolites was performed with the full scan mode of HPLC-MS/MS. There were three peaks (M1, M2, M3) in HPLC-UV chromatogram (Figure 1), of which the retention times and the associated HPLC-MS/MS informations were summarized in Table 3 . The metabolite M1 with the retention time of $4.12 \mathrm{~min}$, showed a signal at $\mathrm{m} / \mathrm{z} 382$ for $[\mathrm{M}+\mathrm{H}]^{+}, 16 \mathrm{Da}(\mathrm{m} / \mathrm{z} 382 \rightarrow 366)$ more than indapamide. Fragmental signal at $\mathrm{m} / \mathrm{z} 148$ corresponded to hydroxyl-indoline structure from broken N-N bond of indapamide. It indicated that the metabolite M1 might be hydroxyl-indapamide. The compound M2 eluting at $9.3 \mathrm{~min}$ possessed the same pseudo-molecule ion, full scan MS/MS spectrum and chromatographic behavior with indapamide. Meanwhile, this compound had two signals at $\mathrm{m} / \mathrm{z} 366,368$ for $[\mathrm{M}+\mathrm{H}]^{+}$, which were the isotopic clusters of chlorine for the molecular ion and $\mathrm{M}+2$ ion with characteristic approximate ratios of $3: 1(\mathrm{M} / \mathrm{M}+2)$. These clusters were also observed in signals of each metabolite. Therefore, it was identified as indapamide without metabolic.
The metabolite M3 with the retention time of 11.7 min, exhibited a signal at $\mathrm{m} / \mathrm{z} 364$ for $[\mathrm{M}+\mathrm{H}]^{+}, 2$ $\mathrm{Da} \quad(\mathrm{m} / \mathrm{z} \quad 364 \rightarrow 366)$ less than indapamide. Fragmental signal at $\mathrm{m} / \mathrm{z} 130$ corresponded to dehydrogen-indoline structure from broken N-N bond of indapamide, which suggested that metabolic transformation of M3 might be formed by direct dehydrogenation or oxidation of indapamide. All informations of two metabolites of indapamide were consistent with the standards and the previous research (34). But indapamide epoxidation reported previously was not found in our study (34).

\section{Influence of CYP-selective inhibitors on indapamide metabolism in vitro}

The isoforms of CYPs involved in indapamide metabolism in human liver microsomes was investigated by incubating indapamide $(100 \mu \mathrm{M})$ with different concentration ranges of CYP-selective inhibitors ( $\alpha$-naphthoflavone, sulfaphenazole, ticlopidine, quinidine, 4-methylpyrazole and ketoconazole). As shown in Figure 1, the formation of these indapamide metabolites was dependent on NADPH according to the changes of the chromatographic peak area of indapamide in the absence or presence of NADPH.

\begin{tabular}{|c|c|c|c|c|c|c|}
\hline \multirow{2}{*}{$\begin{array}{l}\text { Spiked concentration } \\
(\mathrm{ng} / \mathrm{mL})\end{array}$} & \multirow{2}{*}{\multicolumn{3}{|c|}{$\begin{array}{c}\text { Intra-day } \\
\text { Mean } \pm \text { S.D. }{ }^{*}(\mathrm{ng} / \mathrm{mL}) \\
(\text { R.S.D } \%)\end{array}$}} & \multicolumn{3}{|c|}{ Inter-day } \\
\hline & & & & $\begin{array}{l}\text { Mean } \pm \text { S.D.* } \\
(\mathrm{ng} / \mathrm{mL})\end{array}$ & $\begin{array}{l}\text { R.S.D } \\
(\%)\end{array}$ & $\begin{array}{l}\text { Error } \\
(\%)\end{array}$ \\
\hline 2 & $\begin{array}{l}1.98 \pm 0.13 \\
(6.57)\end{array}$ & $\begin{array}{l}2.22 \pm 0.22 \\
(9.91)\end{array}$ & $\begin{array}{l}2.24 \pm 0.14 \\
(6.25)\end{array}$ & $2.15 \pm 0.14$ & 6.74 & 1.3 \\
\hline 80 & $\begin{array}{l}77.7 \pm 3.81 \\
(4.90)\end{array}$ & $\begin{array}{l}86.6 \pm 3.52 \\
(4.07)\end{array}$ & $\begin{array}{l}82.9 \pm 2.43 \\
(2.93)\end{array}$ & $82.4 \pm 4.47$ & 5.43 & -2.8 \\
\hline 1000 & $\begin{array}{l}1195 \pm 40.7 \\
(3.40)\end{array}$ & $\begin{array}{l}992 \pm 38.3 \\
(3.86)\end{array}$ & $\begin{array}{l}987 \pm 54.8 \\
(5.55)\end{array}$ & $1058 \pm 118.6$ & 11.2 & -0.2 \\
\hline
\end{tabular}

*To convert to base, multiply by 1.06 .

Table 2. Validation data for the assay of indapamide in human liver microsomes. $(n=5)$

\begin{tabular}{lllllll}
\hline \multirow{2}{*}{ Spiked concentration $(\mu \mathrm{M})$} & \multicolumn{3}{c}{ Intra-day } & \multicolumn{3}{c}{ Inter-day } \\
& \multicolumn{3}{c}{ Mean \pm S.D. $*(\mu \mathrm{M})($ R.S.D $\%)$} & Mean \pm S.D.* $(\mu \mathrm{M})$ & R.S.D $(\%)$ & Error $(\%)$ \\
\hline \multirow{2}{*}{$1.93 \pm 0.11$} & $1.98 \pm 0.14$ & $2.21 \pm 0.11$ & $2.04 \pm 0.15$ & 7.32 & -3.8 \\
& $(5.73)$ & $(7.24)$ & $(4.93)$ & & & \\
60 & $61.4 \pm 5.43$ & $60.7 \pm 2.38$ & $62.2 \pm 4.19$ & $61.4 \pm 0.73$ & 1.19 & -3.4 \\
& $(8.85)$ & $(3.92)$ & $(6.74)$ & & & -4.1 \\
100 & $102 \pm 9.29$ & $99.9 \pm 7.10$ & $103 \pm 10.0$ & $102 \pm 1.58$ & 1.55 & \\
\end{tabular}

*To convert to base, multiply by 1.06 . 

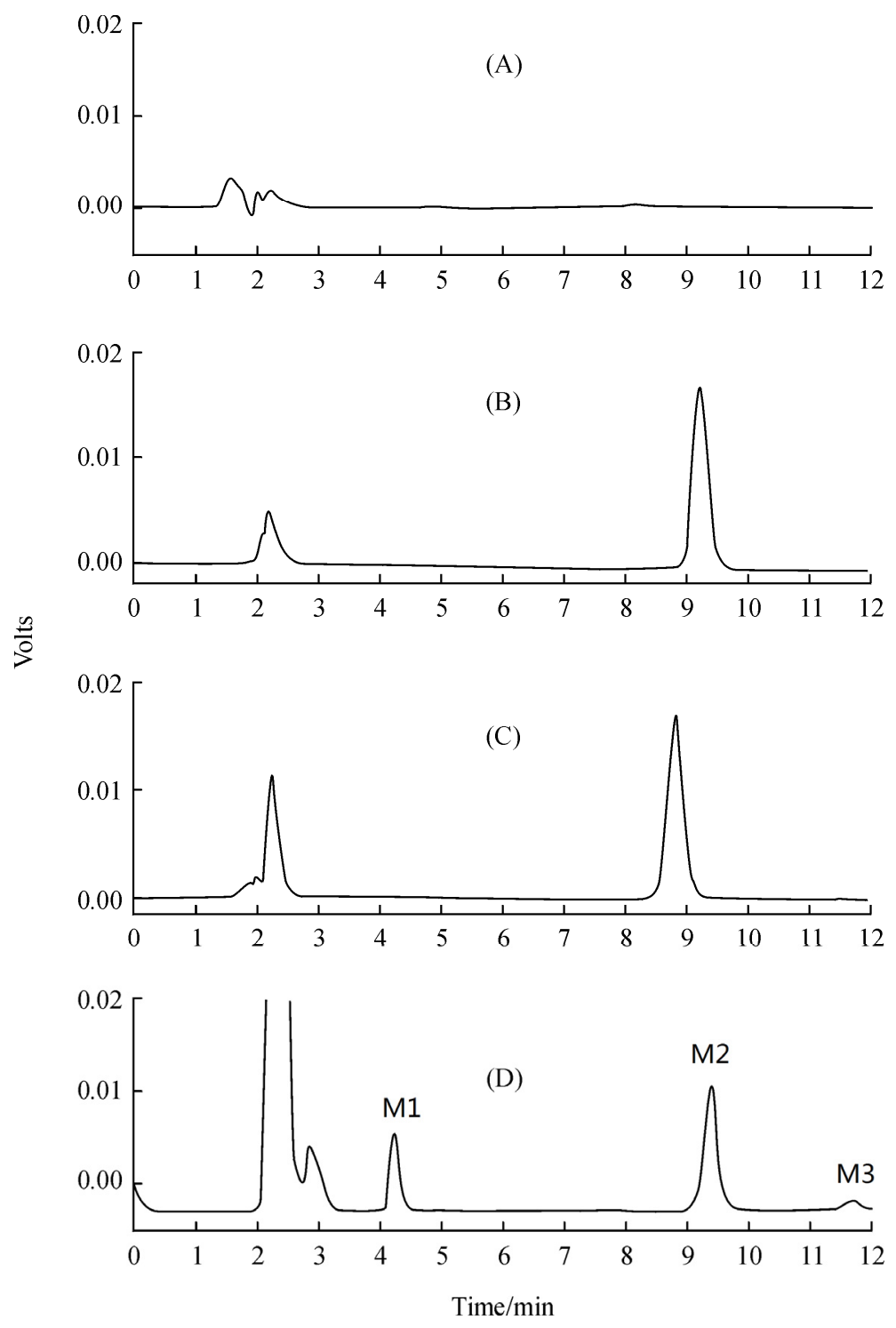

Figure 1. HPLC-UV chromatograms of indapamide in hunman liver microsomal incubation. (A) blank microsome; (B) indapamide standard; (C) indapamide incubated at $37^{\circ} \mathrm{C}$ for $30 \mathrm{~min}$ with human liver microsomes (no NADPH added); (D) indapamide incubated at $37^{\circ} \mathrm{C}$ for 30 min with microsome (NADPH added). M1: indapamide; M2: hydroxyl-indapamide; M3: dehydrogen-indapamide.

Table 3. Identification of indapamide metabolites in human liver microsomes by HPLC/MS-MS.

\begin{tabular}{llll}
\hline No. & Retention time (min) & {$[\mathrm{M}+\mathrm{H}]^{+}$} & Identification \\
\hline 1 & 4.12 & 382,384 & Hydroxyl-indapamide (M1) \\
2 & 9.32 & 366,368 & Indapamide (M2) \\
3 & 11.67 & 364,366 & Dehydrogen-indapamide (M3) \\
\hline
\end{tabular}



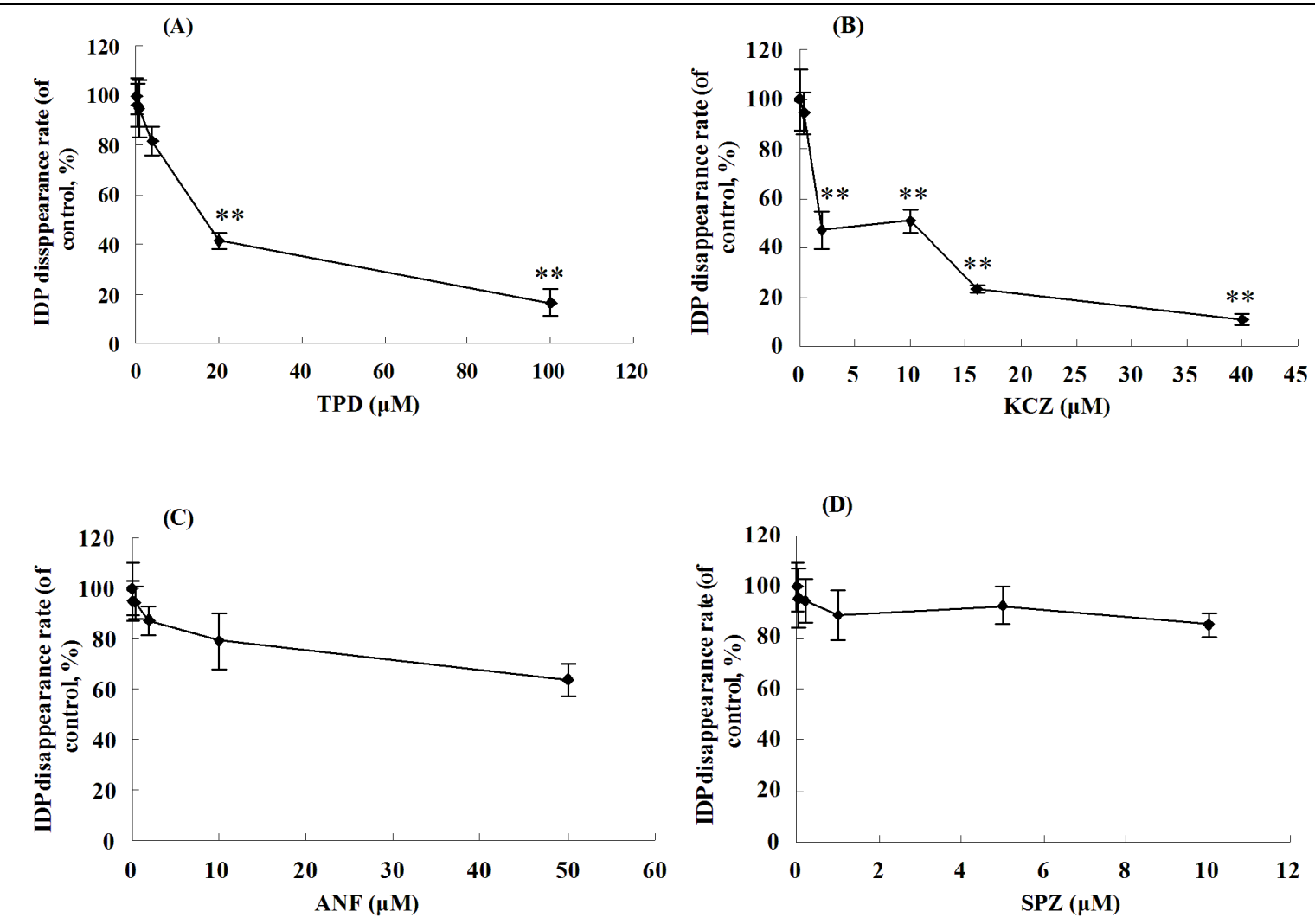

(E)
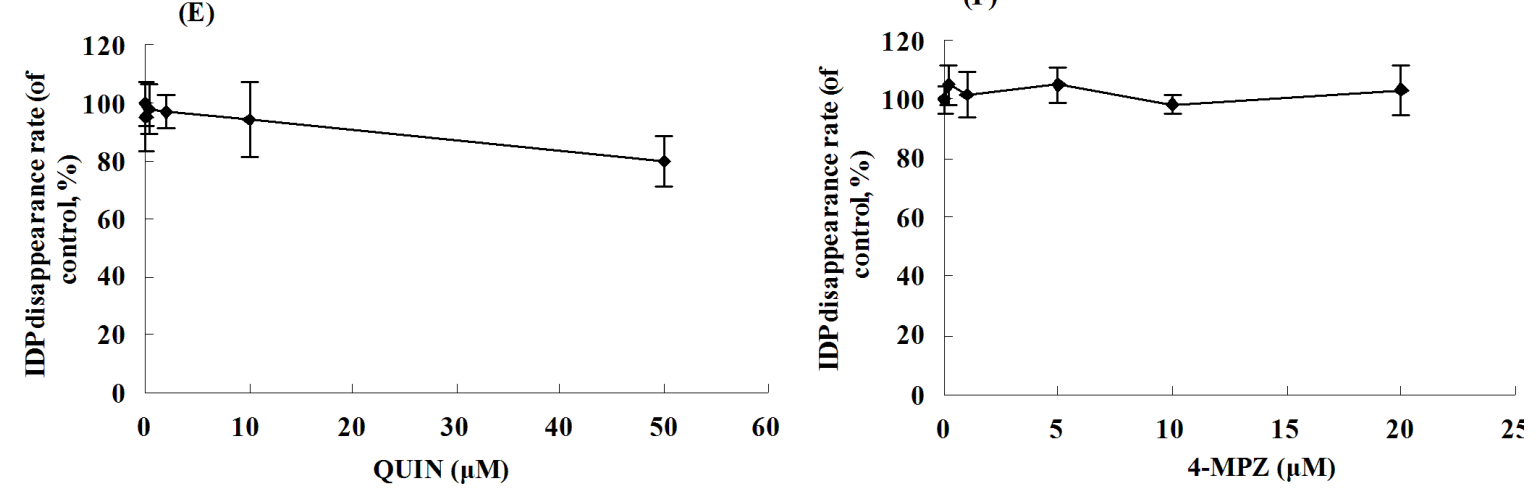

Figure 2. Effects of CYP450 selective inhibitors on the metabolism of indapamide (IDP, $100 \mu \mathrm{M}$ ) in human liver microsomes. The time of incubation was $30 \mathrm{~min}$. (A) CYP2C19 inhibitor ticlopidine (TPD); (B) CYP3A inhibitor ketoconazole (KCZ); (C) CYP1A2 inhibitor $\alpha$-naphthoflavone (ANF); (D) CYP2C9 inhibitor sulfaphenazole (SPZ); (E) CYP2D inhibitor quinidine (QUIN); (F) CYP2E1 inhibitor 4-methylpyrazole (4-MPZ). Symbols represent the disappear rates of indapamide incubated with different CYP inhibitors compared with that of indapamide alone expressed as the percentage of control values (100\%). Data are expressed as mean \pm S.D. $(n=3)$. $* * P<0.01$ compared to indapamide alone.

To determine which isoform of CYPs could be responsible for indapamide metabolism, the effects of six selective-CYP inhibitors on indapamide metabolism were investigated and the results were shown in Figure 2. The increased concentrations of two inhibitors, CYP2C19 inhibitor ticlopidine and CYP3A4 inhibitor ketoconazole, resulted in a significant decrease of indapamide disappearance rates with the maximum inhibitory effects of $83.4 \%$ and $89.1 \%$ $(\mathrm{P}<0.01)$, respectively. CYP1A2 inhibitor $\alpha$-naphthoflavone, $\quad$ CYP2C9 inhibitor 
sulfaphenazole, CYP2D6 inhibitor quinidine and CYP2E1 inhibitor 4-methylpyrazole had little inhibitory effects $(\mathrm{P}>0.05)$ on indapamide metabolism. It suggested that CYP3A4 and CYP2C19 played major roles in indapamide metabolism.

\section{Effects of seven antihypertensive drugs on indapamide metabolism in vitro}

Combination therapy of antihypertensive agents is frequently needed for optimal control of blood pressure. To investigate the interaction of the seven antihypertensive drugs and indapamide in human liver microsomes, different ranges of felodipine, nifedipine, nitrendipine, telmisartan, irbesartan, valsartan and puerarin were incubated with a single concentration $(100 \mu \mathrm{M})$ of indapamide, respectively. As shown in Figure 3, similar tendencies were observed for the effects of felodipine, nifedipine and nitrendipine on indapamide metabolism with the maximum inhibitory rates of $82.6 \%, 72.2 \%$ and $95 \%$, respectively. Telmisartan had inhibitory effects to a lesser degree at the rate of $47.6 \%$, while there were little inhibition $(\mathrm{P}>0.05)$ of valsartan, irbesartan and puerarin tested. These results suggested that felodipine, nifedipine and nitrendipine with the structure of dihydropyridine had significantly inhibitory effects on indapamide metabolism at therapeutic doses in vitro, which meant that potential drug-drug interaction of indapamide and these drugs in pharmacokinetics would possibly occur in vivo.

\section{Effects of felodipine on pharmacokinetics of indapamide in rats in vivo}

Felodipine, a calcium channel blocker, is often combined with indapamide to control blood pressure in Chinese patients of cardiovascular disease in clinical. In addition, there was the significant metabolic interaction of indapamide and felodipine according to the above experiment of the effects of the seven antihypertensive drugs on indapamide metabolism in vitro. Thus, the alteration of indapamide metabolism was examined by determinating its blood concentrations and pharmacokinetic parameters in rats administrated with indapamide and felodipine.
Concentration-time profiles of indapamide in the test group (indapamide $0.25 \mathrm{mg} / \mathrm{kg}$ and 0.9 $\mathrm{mg} / \mathrm{kg}$ felodipine, orally) and the control groups (indapamide $0.25 \mathrm{mg} / \mathrm{kg}$ alone, orally), were depicted in Figure 4. The pharmacokinetic parameters of indapamide in different groups were listed in Table 4. Compared with the control group, felodipine treatment affected the pharmacokinetics of indapamide. The differences of AUC, $t_{1 / 2 z}$ and MRT $_{0-t}$ were statistically significant. In the test group, a slow elimination of indapamide was found that resulted in the disappearance of indapamide in rats within $2.1 \mathrm{~h}$. The MRT of indapamide was significantly increased in the test group when compared with the control group ( 2.7 versus $1.9, \mathrm{P}=0.021)$. In addition, the AUC of indapamide in the test group were significantly higher than the control group (2245.9 versus 1707.2, $\mathrm{P}=0.041$ ).

\section{DISCUSSION}

Indapamide is a traditional diuretic drug for mild and moderate hypertension. Clinically, most patients administrated with indapamide require two or more classes of antihypertensive agents to reach their target blood pressure. This combination therapy has become standard practice in the contemporary management of hypertension to significantly reduce mortality and morbidity in patients with diabetes, stroke, heart failure and myocardial infarction. However, this combination therapy of indapamide and other antihypertensive agents probably leads to potential drug-drug interactions. Though the original Phase I studies of indapamide and its major metabolites in urine are clarified, there are few reports of potential pharmacokinetic action and safety of indapamide on CYP-mediated drug-drug interactions.

Our studies showed that two metabolites of indapamide, hydroxyl-indapamide $(\mathrm{m} / \mathrm{z} 382)$ and dehydrogen-indapamide $(\mathrm{m} / \mathrm{z} 364)$, regarded as major metabolites of indapamide (34), were formed in human liver microsomes in vitro. However, indapamide epoxidation, the third metabolite of indapamide (34), did not show up in our studies. There might be two explanations for this discrepancy: (1) this metabolite containing an epoxy ring which is a ternary ring, was very unstable in the body combined with glutathione rapidly (molecular weight 689); 

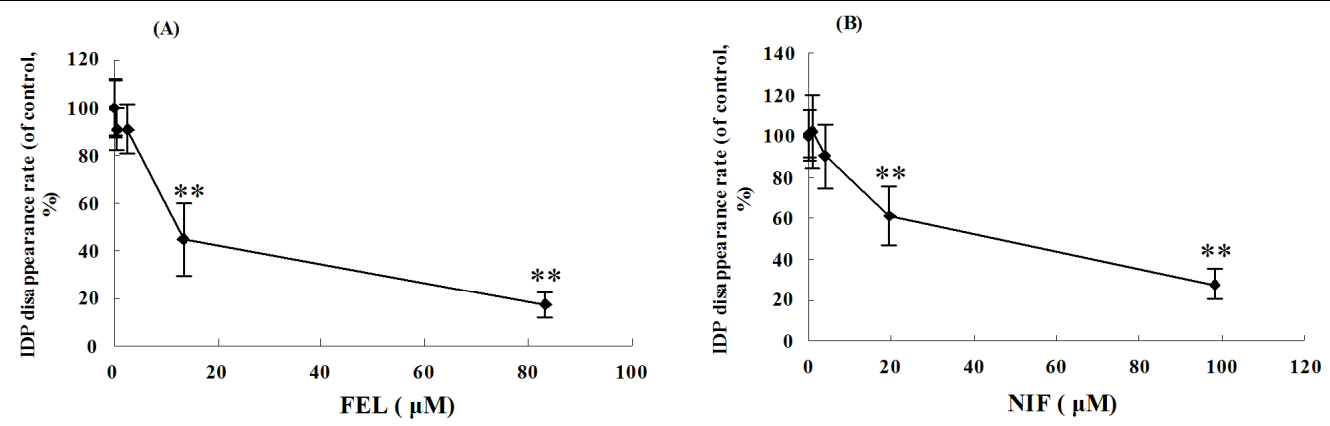

(C)
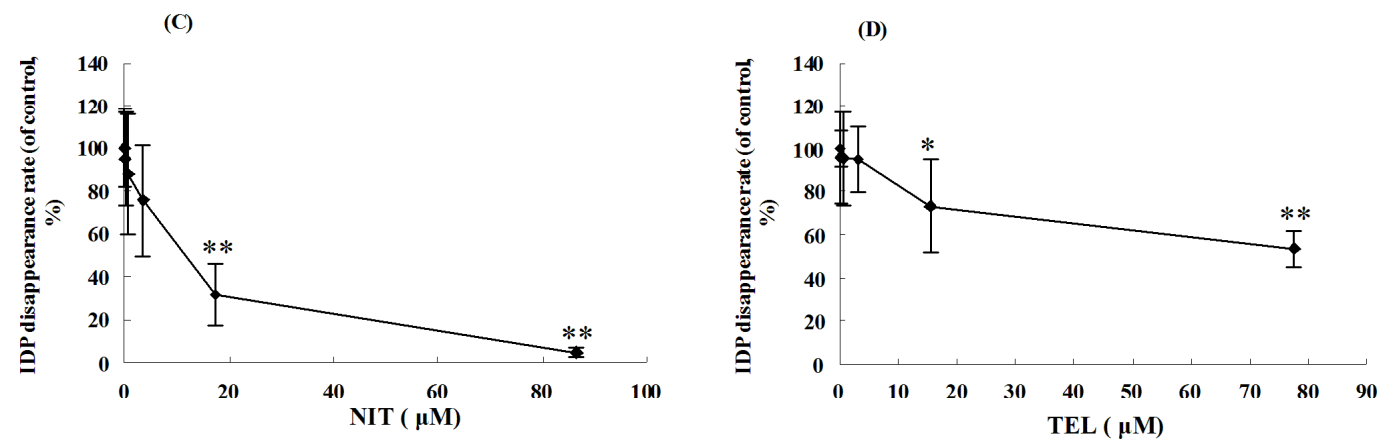

(E)

(F)
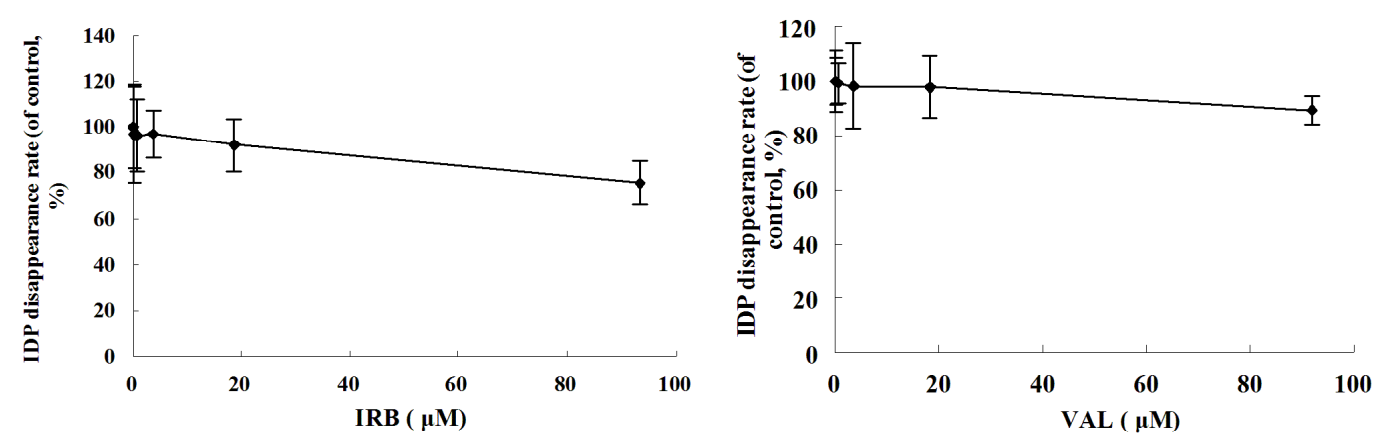

(G)

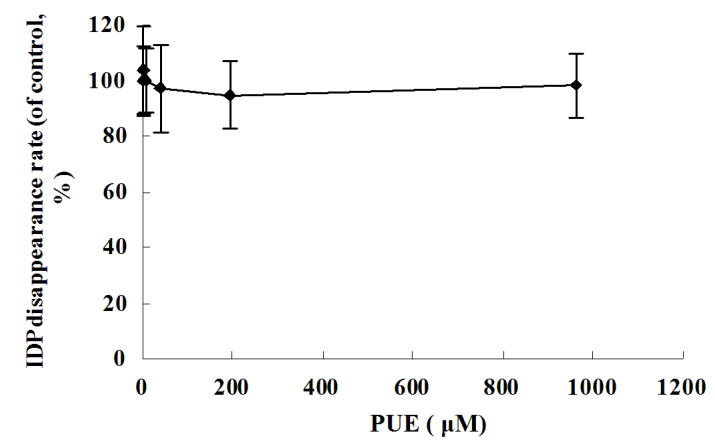

Figure 3. Inhibitory effects of seven antihypertensive drugs on the metabolism of indapamide (IDP, $100 \mu \mathrm{M})$ in human liver microsomes. The time of incubation was $30 \mathrm{~min}$. (A) felodipine (FEL); (B) nifedipine (NIF); (C) nitrendipine (NIT); (D) telmisartan (TEL); (E) irbesartan (IRB); (F) valsartan (VAL); (G) puerarin (PUE). Symbols represent the disappear rates of indapamide incubated with different antihypertensive drugs compared with that of indapamide alone expressed as the percentage of control values $(100 \%)$. Data are expressed as mean \pm S.D. ( $\mathrm{n}=3$ ). ${ }^{*} \mathrm{P}<0.05, * * \mathrm{P}<0.01$ compared to indapamide alone. 


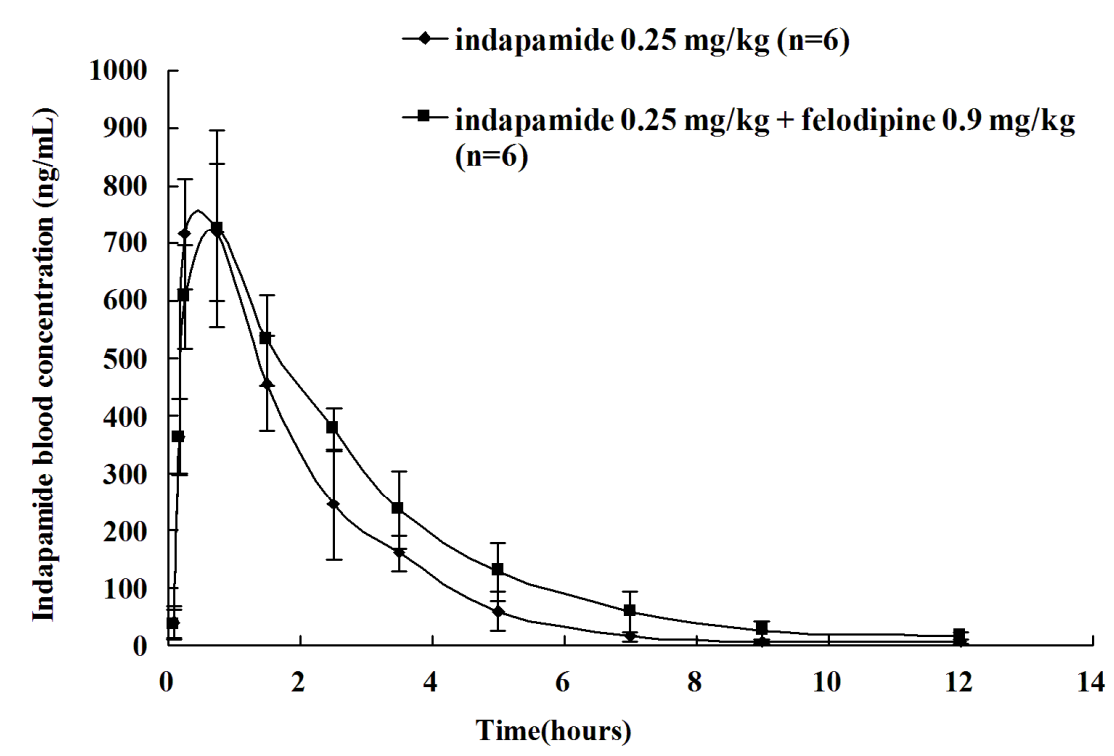

Figure 4. Mean concentration-time profiles of indapamide in rats after oral administration of indapamide $0.25 \mathrm{mg} / \mathrm{kg}$ (suspended in edible oil) alone and indapamide $0.25 \mathrm{mg} / \mathrm{kg}$ combined with felodipine $0.9 \mathrm{mg} / \mathrm{kg}$ (suspended in edible oil). Samples were determined by the HPLC-MS/MS. Data are expressed as mean \pm S.D. for six rats.

Table 4. Pharmacokinetic parameters of indapamide in rats after oral administration of indapamide alone $(0.25 \mathrm{mg} / \mathrm{kg})$ and indapamide $(0.25 \mathrm{mg} / \mathrm{kg})$ combined felodipine $(0.9 \mathrm{mg} / \mathrm{kg})(\mathrm{n}=6)$.

\begin{tabular}{lll}
\hline & Indapamide & Indapamide + felodipine \\
\hline $\mathrm{AUC}_{0-\mathrm{t}}\left(\mu \mathrm{g} / \mathrm{L}^{*} \mathrm{~h}\right)$ & $1707.2 \pm 507.5$ & $2245.9 \pm 396.4^{*}$ \\
$\mathrm{MRT}_{0-\mathrm{t}}(\mathrm{h})$ & $1.9 \pm 0.3$ & $2.7 \pm 0.7^{*}$ \\
$\mathrm{t}_{1 / 2 \mathrm{z}}(\mathrm{h})$ & $1.3 \pm 0.2$ & $2.1 \pm 0.3^{*}$ \\
$\mathrm{~T}_{\max }(\mathrm{h})$ & $0.7 \pm 0.5$ & $0.9 \pm 0.3$ \\
$\mathrm{C}_{\mathrm{Lz} / \mathrm{F}}(\mathrm{L} / \mathrm{h} / \mathrm{kg})$ & $0.013 \pm 0.004$ & $0.009 \pm 0.002$ \\
$\mathrm{~V}_{\mathrm{z} / \mathrm{F}}(\mathrm{L} / \mathrm{kg})$ & $0.024 \pm 0.006$ & $0.027 \pm 0.005$ \\
$\mathrm{C}_{\max }(\mu \mathrm{g} / \mathrm{L})$ & $805.5 \pm 186.0$ & $746.3 \pm 346.1$ \\
\hline \multicolumn{2}{l}{ Data are expressed as mean \pm S.D. for six rats; $* \mathrm{P}<0.05$ compared to indapamide alone group. } \\
\hline
\end{tabular}

(2) volume generated from the metabolic point of view, the reference also reported that it was difficult to detect the indapamide epoxidation in the non-characteristic scan (34).

Inhibition studies of indapamide were carried out in vitro for the most relevant drug-related P450, i.e. CYP1A2, 2C9, 2C19, 2D6, 2E1, and $3 \mathrm{~A} 4$, by using the selective inhibitors of the CYP isoforms in human liver microsomes. Our current study confirmed that CYP3A4 and CYP2C19 played important roles in indapamide metabolism, which was consistent with the reference (34). Therefore, it was important to investigate the potential CYP450-mediated drug-drug interactions of indapamide and other antihypertensive drugs coadministered. Drug-drug interactions of indapamide and seven antihypertensive agents, including felodipine, nifedipine, nitrendipine, telmisartan, irbesartan, valsartan and puerarin, was studied. From the results of the effects of the seven antihypertensive drugs on indapamide metabolism in vitro, the metabolic rates of indapamide in human liver microsome incubated with different agents were different from control vehicle. The disappearance rates of indapamide decreased obviously with the increasing concentrations of felodipine, nifedipine and nitrendipine, respectively. In contrast, irbesartant and elmisartan showed slightly inhibitory effects on indapamide metabolism while there was little inhibition of valsartan and puerarin tested. These results strongly suggested that a relationship existed between the structural and physico-chemical characteristics of the seven antihypertensive drugs. These three drugs, felodipine, nifedipine 
and nitrendipine, are dihydropyridines $\mathrm{Ca}^{2+}$ channel blockers with the fluazifop structure, which are considered to be specific substrates of CYP3A4 (19, 20). Thus, as we found that CYP2C19 and CYP3A4 contributed mainly to indapamide metabolismin this study, these three drugs might have competitive inhibition on indapamide metabolism by CYP3A4 isoform. Although other three antihypertensive drugs, irbesartan, telmisartan and valsartan, are all angiotensin II receptor blockers, their metabolism mechanisms in CYP450 are different. It is well known that the oxidation of irbesartan and valsartan are catalyzed by CYP2C9, and the other metabolism mechanism of valsartan is combination with glucuronic acid (21-23). As for telmisartan, its major metabolic pathway is not responsible for CPY450 but combination with glucuronic acid, but telmisartan is reported to have inhibitory effects on the CYP2C19 activity in vitro (24). Therefore, telmisartan showed slight inhibitory effects on indapamide metabolism due to inhibiting CYP2C19, whereas the inhibition of valsartan and irbesartan was less potent. It is reported that puerarin inhibits the activities of CYP3A, CYP2B1 and CYP2E1 (25). In contrast, little inhibition of puerarin on indapamide metabolism was observed in the present study, possibly due to the selected dose of puerarin not enough for inhibiting CYP450.

Subsequent studies of the effects of felodipine on pharmacokinetics of indapamide in rats, showed that the AUC of indapamide increased significantly after oral coadministration with felodipine in rats $(\mathrm{P}<0.05)$. The elimination of indapamide was facilitated significantly by decreased clearance with the result of the increase of AUC, $t_{1 / 2 z}$ and MRT. It indicated that felodipine could postpone the elimination of indapamide in rats, which might prolong the potency of indapamide in clinical. These results are considered largely dependent on changes of indapamide metabolism caused by CYP3A4 substrate felodipine. Meanwhile, our current studies on indapamide metabolism in human liver microsomes in vitro, had also confirmed a drug-drug interaction between indapamide and felodipine. The inhibitory effects of felodipine on indapamide metabolism in vitro and in vivo may lead to some potential physiological side effects of indapamide in clinical.

\section{CONCLUSION}

Our results indicated that CYP3A4 and
CYP2C19 were the major CYPs of indapamide metabolism in human liver micriosomes, and played vital roles in the drug-drug interaction of indapamide and other antihypertensive drugs coadministered in Chinese patients with cardiovascular disease. It was shown that the coadministration of indapamide and other antihypertensive drugs altered the metabolism of indapamide at different degrees. In addition, felodipine, nifedipine and nitrendipine, were relatively potent inhibitors of indapamide metabolism in vitro. Moreover, felodipine could postpone the elimination of indapamide in rat in vivo, resulting in the increase of $\mathrm{AUC}, \mathrm{t}_{1 / 2 \mathrm{z}}$ and $\mathrm{MRT}_{0-\mathrm{t}}$, which might lead to the potential physiological effects.

The research results demonstrate that combination therapy with indapamide and other antihypertensive drugs may lead to drug-drug interaction and it is important to have further study on the pharmacological and pharmacokinetical effects of coadministration of indapamide and other antihypertensive drugs involved in CYP metabolism for a better clinical application. These works have being carried out in our research laboratories.

\section{ACKNOWLEDGEMENT}

Authors greatly appreciate the valuable discussions and technical assistance of Pro. Tai-jun Hang.

\section{REFERENCES}

1. Chobanian AV, Bakris GL, Black HR, Cushman WC, Green LA, Izzo Jr JL, Jones DW, Materson BJ, Oparil S, Wright Jr JT, Roccella EJ. National Heart, Lung, and Blood Institute Joint National Committee on Prevention, Detection, Evaluation, and Treatment of High Blood Pressure; National High Blood Pressure Education Program Coordinating Committee, The seventh report of the joint national committee on prevention, detection, evaluation, and treatment of high blood pressure: the JNC 7 report. JAMA, 2003; 289:2560-2572.

2. Mogensen CE, Viberti G, Halimi S, Ritz E, Ruilope L, Jermendy G, Widimsky J, Sareli P, Taton J, Rull J, Erdogan G, Leeuw De PW, Ribeiro A, Sanchez R, Mechmeche R, Nolan J, Sirotiakova J, Hamani A, Scheen A, Hess B, Luger A, Thomas SM. Preterax in Albuminuria Regression (PREMIER) Study Group, Effect of low-dose perindopril/indapamide on albuminuria in diabetes: preterax in albuminuria regression: PREMIER. Hypertension, 2003; 41:1063-1071. 
3. Huang SS, Wu TC, Lin SJ, Chen JW. Combination of an ACE inhibitor and indapamide improves blood pressure control, but attenuates the beneficial effects of ACE inhibition on plasma adiponectin in patients with essential hypertension. Circ J, 2009; 73:2282-2287.

4. Patel A, MacMahon S, Chalmers J, Neal B, Woodward M, Billot L, Harrap S, Poulter N, Marre M, Cooper M, Glasziou P, Grobbee DE, Hamet P, Heller S, Liu LS, Mancia G, Mogensen CE, Pan CY, Rodgers A, Williams B. Effects of a fixed combination of perindopril and indapamide on macrovascular and microvascular outcomes in patients with type 2 diabetes mellitus (the ADVANCE trial): a randomised controlled trial. Lancet, 2007; 370:829-840.

5. Graham MJ, Lake BG. Induction of drug metabolism: species differences and toxicological relevance. Toxicology, 2008; 254:184-191.

6. Caruso FS, Szabadi RR, Vukovich RA. Pharmacokinetics and clinical pharmacology of indapamide. Am Heart J, 1983; 106:212-220.

7. Albu F, Georgiţă C, David V, Medvedovici A. Liquid chromatography-electrospray tandem mass spectrometry method for determination of indapamide in serum for single/multiple dose bioequivalence studies of sustained release formulations. J Chromatogr B Analyt Technol Biomed Life Sci, 2005; 816: 35-40.

8. Zhang JL, Qin YW, Zheng X, Qiu JL, Zhao XX, Zou DJ. Combination therapy with angiotensin-converting enzyme inhibitors and indapamide impairs glucose tolerance in Chinese hypertensive patients. Blood Press, 2010; 19:110-118.

9. Ohashi N, Minemura S, Togawa A, Ohyama K. A case of hypokalemia-induced fatal arrhythmia caused by indapamide in an anorexic elderly patient. Clin Exp Nephrol, 2011; [Epub ahead of print].

10. ADVANCE Echocardiography Substudy Investigators and the ADVANCE Collaborative Group. Effects of perindopril-indapamide on left ventricular diastolic function and mass in patients with type 2 diabetes: the ADVANCE echocardiography substudy. J Hypertens, 2011; 29:1439-1447.

11. Leeuw de PW. Combination perindopril/indapamide for the treatment of hypertension: A review. Expert Opin Pharmacother, 2011 [Epub ahead of print]

12. Chen $\mathrm{H}, \mathrm{Fu} \mathrm{LH}$. Effect on left ventricular hypertrophy and heart function, in treating essential hypertension with felodipine combination indapamide vs combination diuretic. Chin J New Drugs Clin Rem, 2001; 20:267-270.

13. Wang W, Xiao Q. Comparison of the effect of indapamide and nifedipine on elderly patients with hyertention. Clin J Med Officer, 2002; 30:21-23.
14. Song JL, Cheng GC, Pang WY. The experience of low-dose of nitrendipine and indapamide combined application. Chin J Med, 1998; 83:394-396.

15. Zhou GB, Sun KY, Li JC, Chen YD, Qian Z. The effect of combined telmisartan with indapamide sustained release on pulse pressure and morning blood pressure surge in older essential hypertensive patients. Chin J Hypertens, 2009; 17:406-409.

16. Kang AN. Irbesartan plus idapamide for hypertension. J Clin Exp Med, 2007; 6: 49-50.

17. Xie QY, Wang YJ, Sun ZL, Yang TL. Effects of valsartan and indapamide on plasma cytokines in essential hypertension. J Cent South Univ (Med Sci), 2006; 31:629-634.

18. Liang G, He QL, Liu JW. The effect of combined puerarin with indapamide on pulmonary heart failure. Guangdong Med J, 2005; 26:705-706.

19. Hunt BA, Self TH, Lalonde RL, Bottorff MB. Calcium channel blockers as inhibitors of drug metabolism. Chest, 1989; 96:393-399.

20. Kirch W, Kleinbloesem CH, Belz GG. Drug interactions with calcium antagonists. Pharmacol Ther, 1990; 45:109-136.

21. Bourrié M, Meunier V, Berger Y, Fabre G. Role of cytochrome P-4502C9 in irbesartan oxidation by human liver microsomes. Drug Metab Dispos, 1999; 27:288-296.

22. Waldmeier F, Flesch G, Müller P, Winkler T, Kriemler HP, Bühlmayer P, Gasparo De M. Pharmacokinetics, disposition and biotransformation of [14C]-radiolabelled valsartan in healthy male volunteers after a single oral dose. Xenobiotica, 1997; 27:59-71.

23. Nakashima A, Kawashita H, Masuda N, Saxer C, Niina M, Nagae Y, Iwasaki K. Identification of cytochrome $\mathrm{P} 450$ forms involved in the 4-hydroxylation of valsartan, a potent and specific angiotensin II antagonist, in human liver microsomes. Xenobiotica, 2005; 35:589-602.

24. Wienen W, Entzeroth M, Meel van JCA, Stangier J, Busch U, Ebner T, Schmid J, Lehmann H, Matzek K, Kempthorne-Rawson J, Gladigau V, Hauel NH. A review on telmisartan: a novel, longacting angiotensin II-receptor antagonist. Cardiovasc Drug Rev, 2000; 18:127-156.

25. Guerra MC, Speroni E, Broccoli M, Cangini M, Pasini P, Minghett A, Crespi-Perellino N, Mirasoli M, Cantelli-Forti G, Paolini M. Comparison between chinese medical herb Pueraria lobata crude extract and its main isoflavone puerarin antioxidant properties and effects on rat liver CYP-catalysed drug metabolism. Life Sci, 2000; 67:2997-3006.

26. Wójcikowski J, Daniel WA. Influence of antidepressant drugs on chlorpromazine metabolism in human liver--an in vitro study. Pharmacol Rep, 2010; 62:1062-1069.

27. Hasegawa $T$, Hara K, Kenmochi $T$, Hata S. In 
vitro metabolism of dorzolamide, a novel potent carbonic anhydrase inhibitor, in human liver microsomes. Drug Metab Dispos, 1994; 22:916-921.

28. Liu YT, Hao K, Liu XQ, Wang GJ. Metabolism and metabolic inhibition of gambogic acid in human liver microsomes. Acta Pharmacol Sin, 2006; 27:1253-1258.

29. Chung HJ, Choi YH, Kim SH, Lee MG. Effects of enzyme inducers and inhibitors on the pharmacokinetics of intravenous ipriflavone in rats. J Pharm Pharmacol, 2006; 58:449-457.

30. Jiang Y, Kuo CL, Pernecky SJ, Piper WN. The detection of cytochrome P450 2E1 and its catalytic activity in rat testis. Biochem Biophys Res Commun, 1998; 246:578-583.

31. $\mathrm{Yu} \mathrm{L}$, Waxman DJ. Role of cytochrome P450 in oxazaphosphorine metabolism. Drug Metab Dispos, 1996; 24:1254-1262.
32. Ponnusankar S, Pandit S, Venkatesh M, Bandyopadhyay A, Mukherjee PK. Cytochrome P450 inhibition assay for standardized extract of Terminalia chebula Retz. Phytother Res, 2011; 25:151-154.

33. Jain DS, Subbaiah G, Sanyal M, Pande UC, Shrivastav P. Liquid chromatography-tandem mass spectrometry validated method for the estimation of indapamide in human whole blood. J Chromatogr B Analyt Technol Biomed Life Sci, 2006; 834:149-154.

34. Sun H, Moore C, Dansette PM, Kumar S, Halpert JR, Yost GS. Dehydrogenation of the Indoline-Containing Drug 4-Chloro-N-(2-methyl-1-indolinyl)-3-sulfamoylbe nzamide (Indapamide) by CYP3A4: Correlation with in Silico Predictions. Drug Meta and Dispos, 2009; 37:672-684. 